\title{
MULTIPLE NON-LUETIC ANEURYSMS IN YOUNG NIGERIANS
}

\author{
BY \\ D. GORDON ABRAHAMS AND W. PETER COCKSHOTT \\ From the Departments of Medicine and Radiology, University College Hospital, Ibadan, Nigeria
}

Received March 27, 1961

\begin{abstract}
Anyone who works in a developing, tropical territory such as West Africa is immediately impressed by the plethora of unusual clinical material which abounds. It is natural that this usually takes the form of advanced, florid, examples of clinical and pathological states which are already well recognized. But sometimes diseases are seen which seem to be peculiar to those countries or to the people who live in them. Recently we have seen several patients with multiple aneurysms of the great vessels, a condition which seems to be a clinical entity. In this paper we report a series of seven such patients, six of whom were first seen between September 1958 and September 1959; the seventh patient was investigated in November 1960.
\end{abstract}

\section{Clinical Material}

The mode of presentation of these patients was interesting and varied. Two presented in frank congestive heart failure (Cases 2 and 5). Two other patients came to hospital because of pulsatile swellings in the neck (Case 1) and in the right supraclavicular fossa (Case 3). Case 4 complained of chest pain and cough; she had received antituberculous chemotherapy elsewhere for nine months because the chest X-ray showed a mediastinal mass which was thought to be glandular in origin, but without benefit. Another patient (Case 6) was first seen when she was about 24 weeks pregnant; a chest X-ray revealed miliary tuberculosis and aneurysmal dilatation of the aorta. The last patient (Case 7), a young man of 24, took advantage of an offer to have his chest X-rayed free of charge at an exhibition to celebrate Nigeria's Independence. Until then he was free of symptoms. Thus five of the seven patients had symptoms directly referrable to their vascular lesions.

The clinical features of these cases will not be described in great detail; the relevant facts are summarized in Table I. As far as could be ascertained there was no familial incidence; there were five women and two men in the series. All were Yorubas, the dominant tribe in the Western Region of Nigeria. Their ages ranged from 16 to 37 years with an average of 27 years. The heart was clinically enlarged in three patients (Cases 2, 3, and 5), but aortic incompetence was present in only two of these (Cases 3 and 5); this was reflected in the wide pulse pressure. An important physical sign was the diminution in the volume, or complete absence, of the pulses in one or both of the upper extremities. Thus in Case 1 the pulses were absent in the right arm and diminished in the left arm. In Case 3 no pulses were palpable in the left arm. In Case 4 the pulses were very small in both arms, and in Case 6 the left radial and brachial pulses were difficult to feel.

Follow up of patients has been difficult and not entirely satisfactory. One patient (Case 2) died, and the necropsy findings are described below. Three patients are alive and in reasonable health 21,15 , and 29 months respectively after they were first examined (Cases 1,3 , and 4). One patient (Case 6) was followed for six months; she then defaulted and all efforts to trace her failed. Similarly, 
TABle I. Clinical Findings and $\mathrm{S}$

\begin{tabular}{|c|c|c|c|c|c|c|c|}
\hline \multirow{2}{*}{ Case No. } & \multirow{2}{*}{ Sex } & \multirow{2}{*}{ Age* } & \multirow{2}{*}{ Clinical findings } & \multicolumn{4}{|c|}{ Blood pressures } \\
\hline & & & & R. Arm & L. Arm & R. Leg & L. Leg \\
\hline 1. F.E. & $F$ & 16 & - & Unrecordable & $90 / 70$ & $120 / 70$ & $130 / 80$ \\
\hline 2. E.J. & $\mathrm{F}$ & 35 & $\begin{array}{l}\text { Cardiac enlargement } \\
\text { Congestive heart failure }\end{array}$ & $110 / 70$ & $110 / 70$ & \multicolumn{2}{|c|}{ Not recorded } \\
\hline 3. A.A. & $\mathrm{F}$ & 22 & $\begin{array}{l}\text { Wasting \& "clawing" of } \mathbf{R} \text {. } \\
\text { hand } \\
\text { Cardiac enlargement } \\
\text { Aortic incompetence }\end{array}$ & $140 / 0$ & Unrecordable & $190 / 55$ & $195 / 60$ \\
\hline 4. S.A. & $\mathbf{F}$ & 30 & - & $90 / 70$ & $80 / 60$ & $160 / 110$ & $160 / 11 C$ \\
\hline 5. A.B. & $\mathbf{M}$ & 37 & $\begin{array}{l}\text { Cardiac enlargement } \\
\text { Aortic incompetence } \\
\text { Congestive heart failure }\end{array}$ & $140 / 50$ & $135 / 60$ & $160 / 60$ & $170 / 60$ \\
\hline 6. D.D. & F & 25 & $\begin{array}{l}\text { Cyesis } \\
\text { Miliary tuberculosis }\end{array}$ & $130 / 70$ & $85 / 60$ & $135 / 95$ & $135 / 10 \mathrm{C}$ \\
\hline 7. S.O. & $\mathbf{M}$ & 24 & - & $135 / 80$ & $140 / 75$ & $150 / 85$ & $150 / 85$ \\
\hline
\end{tabular}

* Age on first attendance.

Case 5 was never seen after discharge from hospital. The last patient (Case 7) is a recent addition to the series, and has been observed for only three months.

The electrocardiogram showed no particular abnormality in these patients, and the test was not helpful. When heart failure was present non-specific left ventricular "strain" patterns were seen; otherwise the tracings were within normal limits.

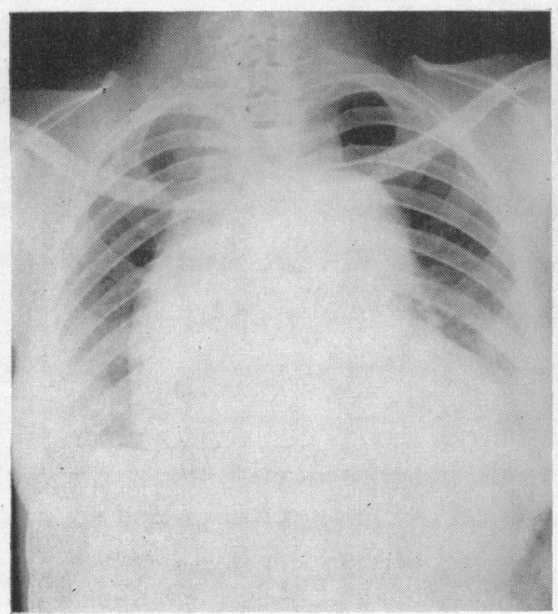

(A)

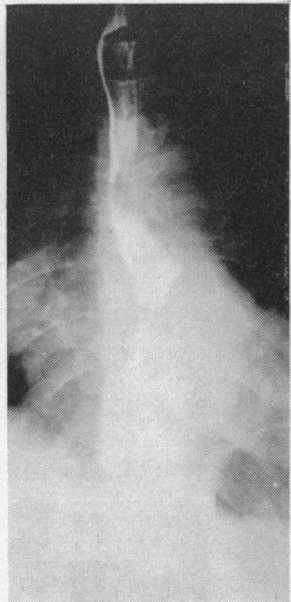

(B)

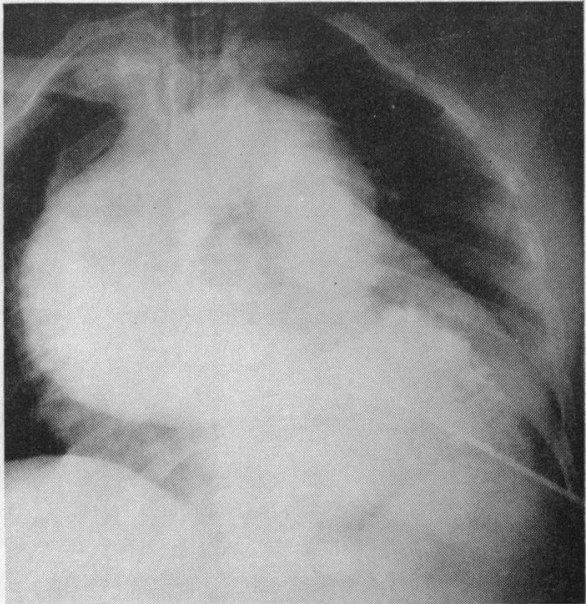

(C)

Fig. 1.-(Case 3). (A) P.A. projection suggests that the right cardiac outline is formed by the dilatation of the ascending aorta. (B) Esophageal displacement indicates involvement of the whole of the descending thoracic aorta. (C) Left ventricular angiogram in partial left anterior oblique position. The aortic valve ring is dilated. There is gross aneurysmal dilatation of the ascending part and arch of the aorta with dilatation of the innominate artery, and part of the descending thoracic aorta. The ascending aorta forms a large part of the right border of the cardiac silhouette. 
JF ANEURYSMS in SEVEn Nigerians

\begin{tabular}{|c|c|c|}
\hline Follow up & Sites of aneurysms & Other angiocardiographic features \\
\hline live, 21 months & $\begin{array}{l}\text { Ascending aorta, innominate; } \mathbf{R} \text {. common carotid } \\
\text { artery }\end{array}$ & $\begin{array}{l}\text { R. subclavian not visualized } \\
\text { L. carotid not demonstrated }\end{array}$ \\
\hline Jied, Necropsy & $\begin{array}{l}\text { Ascending, arch, thoracic, and abdominal aortæ; } \\
\text { innominate, L. subclavian, L. common carotid } \\
\text { arteries }\end{array}$ & $\begin{array}{l}\text { Considerable calcification of aneurysms, } \\
\text { with evidence of massive clotting }\end{array}$ \\
\hline live, 15 months & $\begin{array}{l}\text { Ascending, arch, thoracic aortæ, innominate, R. and } \\
\text { L. common carotids, R. subclavian arteries }\end{array}$ & \\
\hline live, 29 months & $\begin{array}{l}\text { Ascending, arch, and thoracic aortæ; innominate, } \\
\text { R. common carotid, R. subclavian arteries }\end{array}$ & \\
\hline Jo follow up & $\begin{array}{l}\text { Ascending, arch, and thoracic aortæ; innominate } \\
\text { artery }\end{array}$ & \\
\hline $\begin{array}{l}\text { ix months follow up. } \\
\text { Defaulted }\end{array}$ & $\begin{array}{l}\text { Ascending, arch and thoracic aortæ; innominate, } \\
\text { R. common carotid, L. subclavian arteries }\end{array}$ & Arterial "pouching" \\
\hline live, 3 months & Arch, thoracic and abdominal aortæ & \\
\hline
\end{tabular}

Radiological examination was most informative, and in particular angiocardiography was extensively employed to define the number, extent, and anatomical situations of the aneurysms. Originally angiocardiography was performed by direct percutaneous ventricular puncture under general anæsthesia. The position of the wide-bore needle was checked by monitoring the pressure. More recently the Seldinger technique has been used, the catheter being passed into the aorta or left ventricle from one or other femoral artery.

The locations of the aneurysms in individual patients are set out in Table I. It will be seen that in every instance the ascending part and arch of the aorta were involved together with several of the main vessels arising from the aorta. In some instances the aneurysmal process spread down the thoracic aorta and even involved the abdominal aorta. Aneurysms of the main vessels in the limbs, such as the femoral and axillary arteries, were not seen. The lesions did not appear to spread far peripherally, but were limited to the central arterial trunks.

The size of the aortic aneurysms varied considerably. In some instances (Cases 2, 3, and 5) they were enormous. Fig. 1 shows the chest X-ray and angiocardiogram of Case 3 . There is gross dilatation of the aortic ring and ascending aorta, together with enlargement of the aortic knuckle (Fig. 1C). The angiocardiogram suggests that the aortic wall is markedly thickened in these regions. A further considerable dilatation of the abdominal aorta is also present (Fig. 2). Case 5 shows much the same features (Fig. 3). In addition the over-penetrated view (Fig. 3B) shows how the lower part of the œsophagus is displaced to the left presumably by a large localized dilatation of the descending thoracic aorta.

Sometimes the aortic involvement was not so severe. For example in Case 1 (Fig. 4A) the aortic dilatation, although obvious, was not gross, but aneurysmal dilatation of the innominate artery and its branches was most pronounced (Fig. 4B). Indeed the innominate artery was larger than the descending thoracic aorta.

In one patient (Case 6) some of the vascular lesions appeared to be of a different kind. In addition to aneurysmal enlargement of the ascending part and arch of the aorta there was a peculiar pouching of the innominate artery. Lower down in the lower thoracic aorta at the levels of D.10 and D.12 


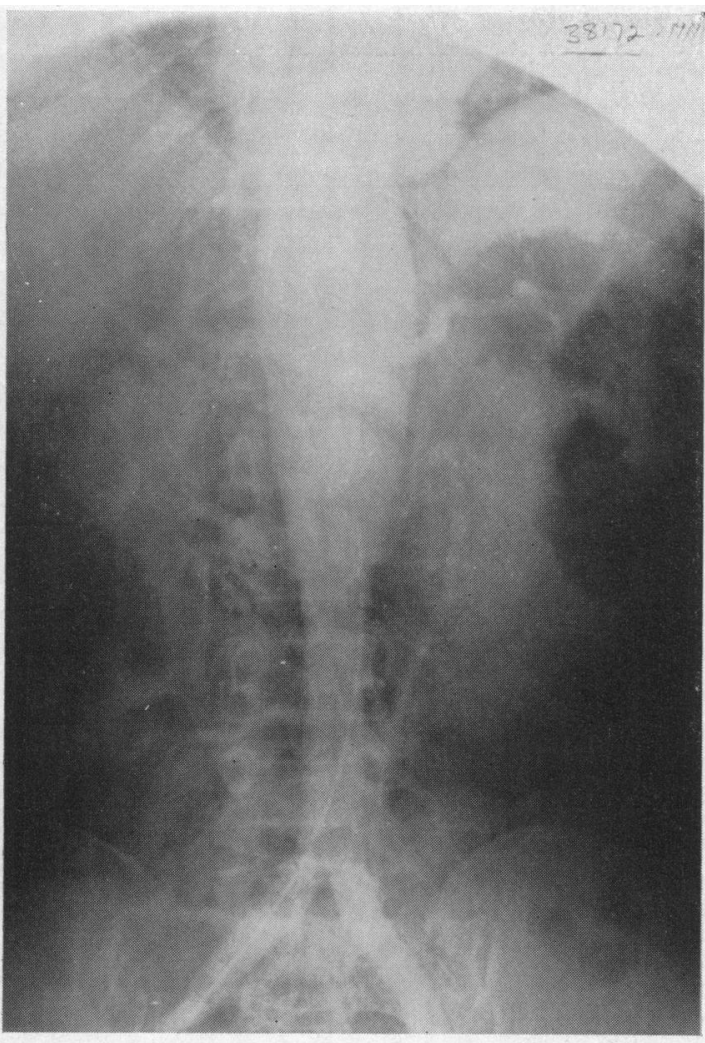

Fig. 2.-(Case 3). Retrograde catheter aortogram demonstrating that aneurysmal dilatation extends to the level of the renal arteries. two further pouches were visualized (Fig. 5B). This was the only patient in whom lesions of this nature were seen.

The results of further laboratory investigations that were carried out on these patients are shown in Table II below. The hæmoglobin genotype was AA in six patients and AS in the seventh. Thus the lesion bears no relationship to the hæmoglobinopathies. The serum cholesterol in five patients was within the normal range for the race and social group (Edozien, 1958). Two individuals had raised total eosinophil counts, but even these were not particularly remarkable for this population which is heavily infested with parasites.

Necropsy Material

Only one patient in this series came to necropsy. This was a 35-year-old woman who was admitted to hospital with severe congestive heart failure. The chest X-ray showed cardiac enlargement with gross widening of the vascular pedicle, and a very large calcified aortic knuckle. Angiocardiography confirmed the presence of multiple aneurysms (Fig. 6). Death occurred five weeks after admission to hospital.

At necropsy, the heart was enlarged due to left ventricular hypertrophy. There was aneurysmal dilatation of the thoracic aorta throughout its length, and also of the major part of the abdominal aorta (Fig. 7). From the thoracic aorta the process had spread up into the innominate artery and its major branches, and also to the origins of the left common carotid and subclavian arteries. The enlargement of the aorta was due to a series of large saccular dilatations, some of which contained considerable ante-mortem clot. These dilatations were calcified, particularly at their upper and lower margins, so that the aorta seemed to be composed of a series of balloon-like dilatations separated by narrow valvular constrictions.

Histological examination showed complete loss of the normal architecture particularly at the sites of constriction, the muscle coats being largely destroyed and replaced by dense fibrous collagenous tissue in part calcified. There was some thickening and narrowing of the vasa vasorum with moderate intimal proliferation, but no sign of periarteritis. There was no evidence of syphilis nor of any acute inflammatory change.

\section{DisCUSSION}

At this stage no firm statement can be made about the prognosis of this condition, for unfortunately our follow up has either been unsatisfactory, or of too short duration. Common sense suggests that the number and size of the aneurysms will be important, though rupture has not occurred in any of our cases; aortic incompetence must also be a serious complication. It is possible that direct extension up the common carotid and internal carotid arteries might lead to central nervous complications, but we have not observed this. Involvement of the abdominal aorta can have serious consequences, and we have recently studied a Nigerian youth (Abrahams and Parry, 1961) in whom a large and extensive aneurysm of the abdominal aorta caused stenosis of the left renal artery with 


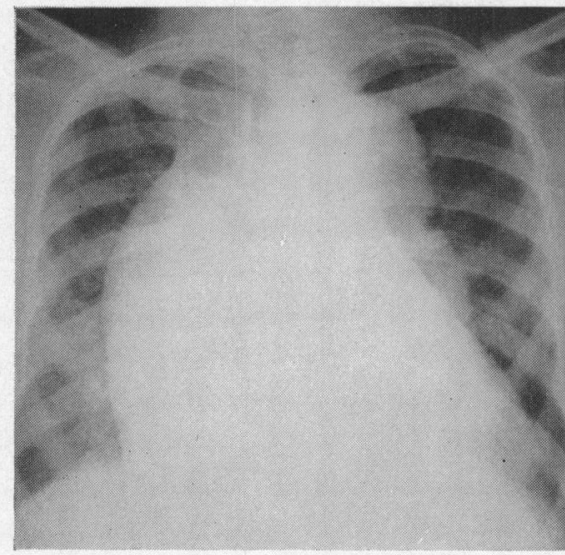

(A)

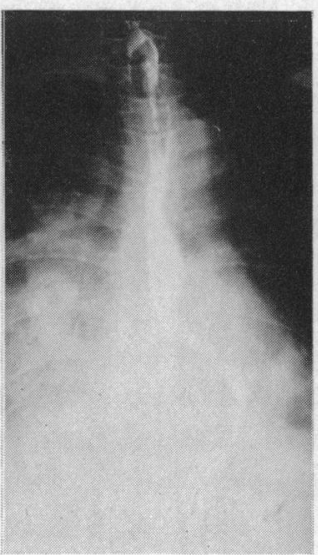

(B)

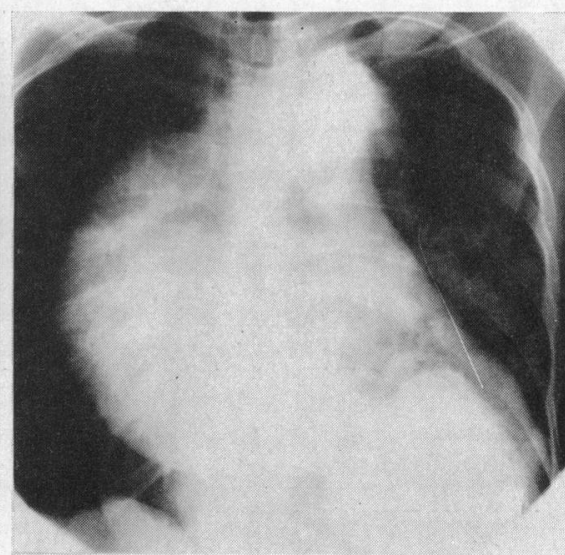

(C)

Fig. 3.-(Case 5). (A) P.A. projection revealing gross dilatation of the ascending arch and descending parts of the aorta. (B) Barium swallow demonstrates that the aortic dilatation displaces the lower thoracic osophagus. (C) Left ventricular angiogram confirms findings of plain films. Aortic ring is dilated and left ventricular hypertrophy is present.

severe hypertension. Removal of the left kidney caused a dramatic fall in his blood pressure which has subsequently remained normal. The aortograms obtained from Case 7 in this series are reproduced in Fig. 8. In addition to the aneurysm of the arch and descending thoracic aorta there is a dilatation of the abdominal aorta ending at the level of the origin of the renal arteries, and we question whether hypertension will arise in this patient in the future if the process extends lower down the aorta. A similar state of affairs is present in Case 3 (Fig. 2). The systolic blood pressure in this patient's legs is $190-195 \mathrm{~mm}$. $\mathrm{Hg}$ although this may be due to the effect of severe aortic incom-

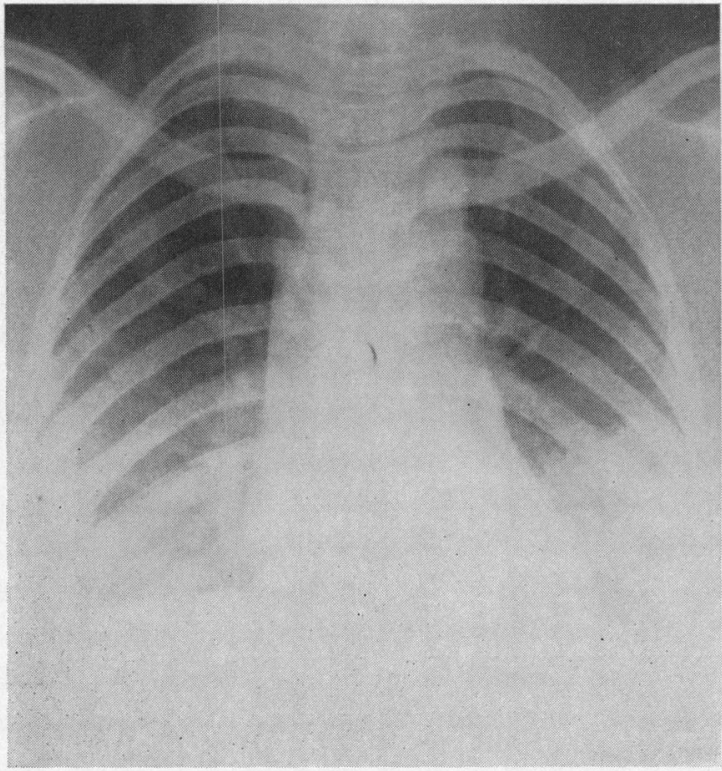

(A)

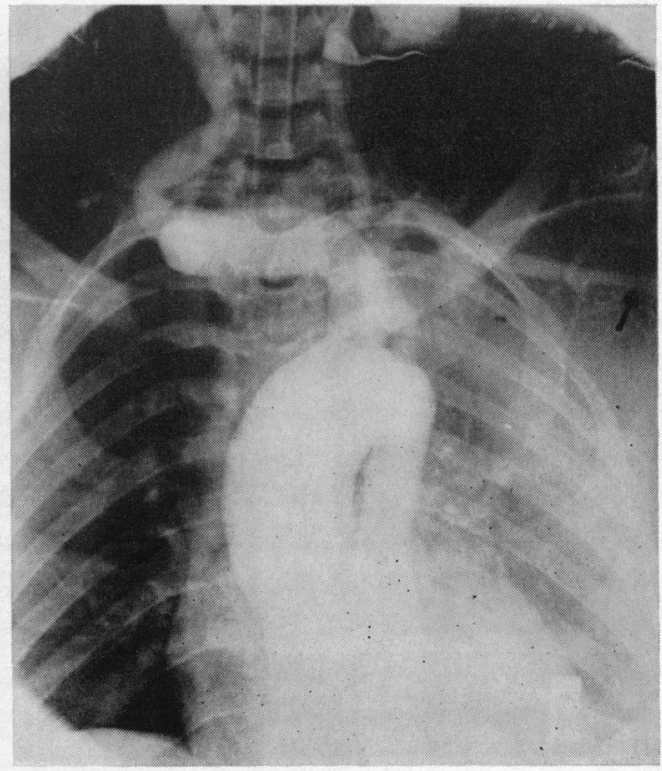

(B)

Fig. 4.-(Case 1). (A) Wide upper mediastinum due to dilated aorta and great vessels. (B) Left ventricular angiogram reveals dilated ascending part and arch of aorta, enormous tortuous innominate artery and dilated right carotid. Left carotid and right subclavian arteries do not fill. Arrow indicates a narrowed segment of the left axillary artery. 


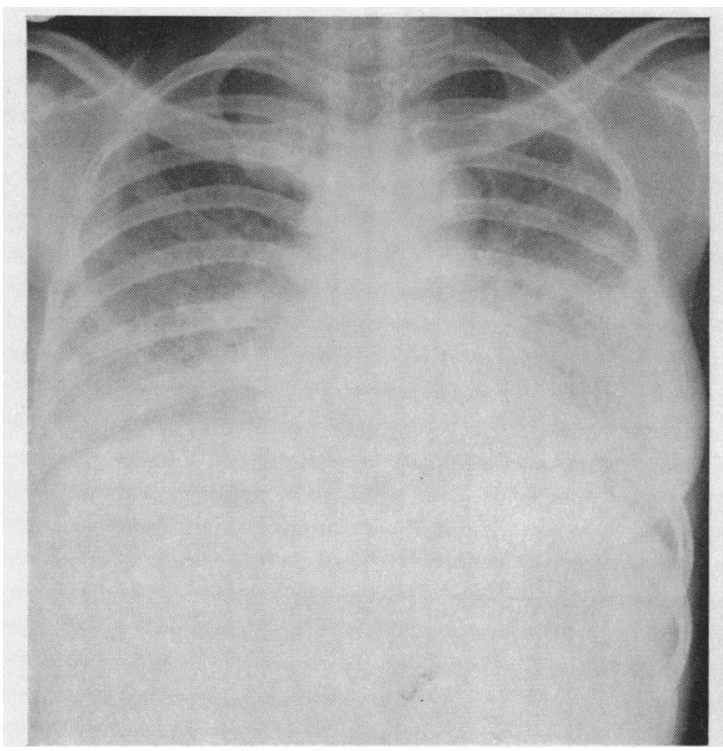

(A)

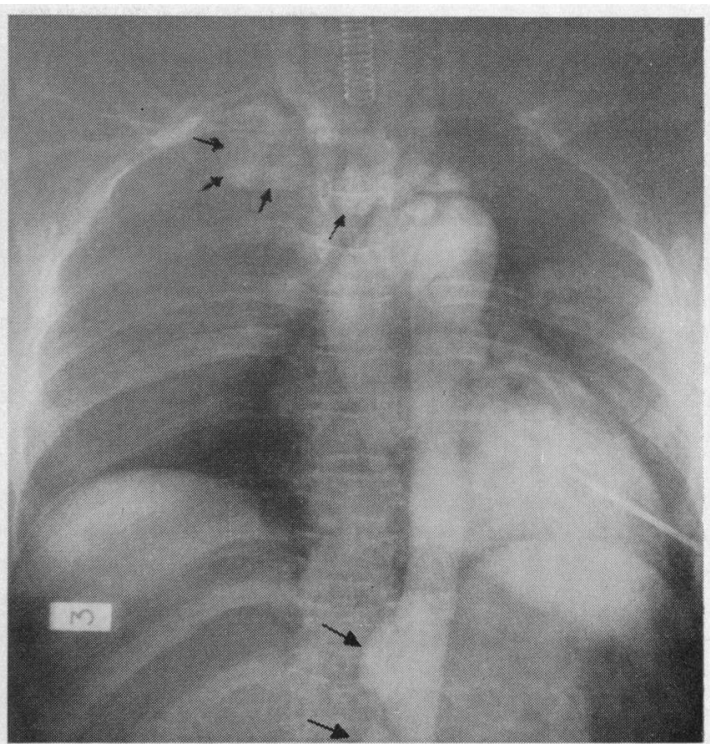

(B)

FIG. 5.-(Case 6). (A) Lung fields show mottling due to miliary tuberculosis. A large right upper mediastinal mass is present. (B) Left ventricular angiogram demonstrates multiple aneurysms of the great vessels arising from the aorta. The large innominate aneurysm opacifies poorly, suggesting the presence of clot. The two lower arrows point to the outpouchings of the descending aorta.

petence. We think, therefore, that these aneurysms may be particularly dangerous when they involve the abdominal aorta.

The atiology of the disease is speculative, but there are several possibilities to be considered, and the first of these is syphilis. It will be seen from Table II that six out of the seven patients had negative Kahn reactions. The one exception was a pregnant woman with miliary tuberculosis; a negative treponema immobilization test confirmed the suspicion that this was a "false positive" reaction. It must also be remembered that yaws is endemic in Southern Nigeria, so that a positive Kahn reaction can well be due to this. The youth of our patients, the diversity of the aneurysms, the negative serology, and the absence of any histological evidence of syphilis in the one patient who died, serve to exclude luetic disease.

TABLE II

H

\begin{tabular}{|c|c|c|c|c|c|c|}
\hline Case No. & Sex & Age & $\begin{array}{l}\text { Kahn } \\
\text { reaction }\end{array}$ & $\begin{array}{l}\text { Hæmoglobin } \\
\text { genotype }\end{array}$ & $\begin{array}{c}\text { Total serum } \\
\text { cholesterol } \\
\text { mgm. } \%\end{array}$ & $\begin{array}{l}\text { Eosinophil } \\
\text { count }\end{array}$ \\
\hline 1. F. E. & F & 16 & -ve & $\mathbf{A A}$ & 136 & $2300 / \mathrm{cm} . \mathrm{m}$ \\
\hline 2. E. J. & $\mathbf{F}$ & 35 & $-\mathrm{ve}$ & $\mathbf{A A}$ & - & N.D.* \\
\hline 3. A. A. & $\mathbf{F}$ & 22 & $-\mathrm{ve}$ & $\mathbf{A A}$ & 155 & $1100 / \mathrm{cm} . \mathrm{m}$ \\
\hline 4. S. A. & $\mathbf{F}$ & 30 & $-\mathrm{ve}$ & $\mathbf{A A}$ & 131 & 57/cm.m. \\
\hline 5. A. B. & $\mathbf{M}$ & 37 & $-v e$ & AA & 135 & N.D.* \\
\hline 6. D. D. & $\mathbf{F}$ & 25 & $+v e$ & AS & - & 497/cm.m. \\
\hline 7. S. O. & $\mathbf{M}$ & 24 & -ve & AA & 153 & N.D.* \\
\hline
\end{tabular}

* N.D. $=$ Normal Differential White Cell Count. 


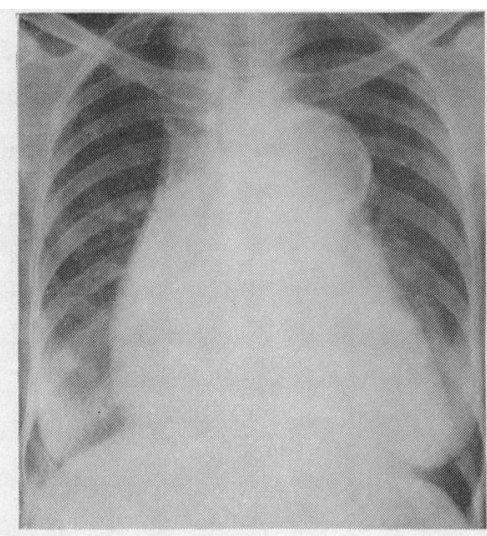

(A)

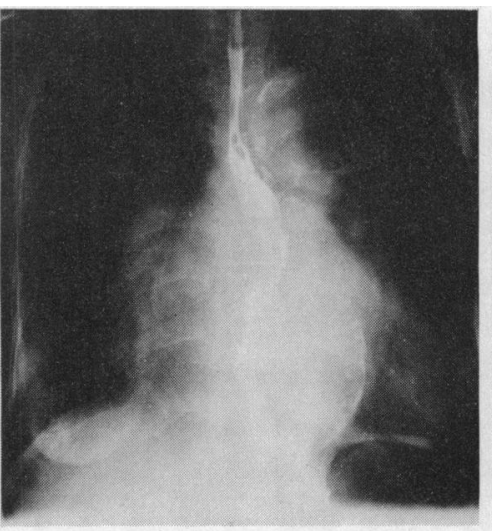

(B)

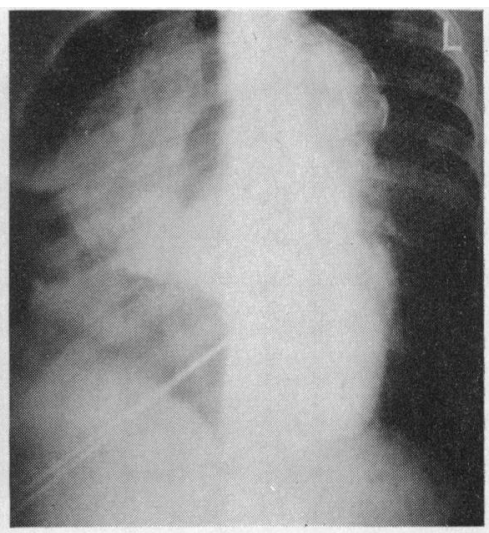

(C)

FIG. 6.-(Case 2). (A) Enormous heart and grossly dilated and unfolded aorta. Mural calcification present in ascending portion and arch. (B) Penetrated view shows calcification in dilated arch and in dilated pouches of descending aorta. Esophagus displaced by aneurysms. (C) Left ventricular angiogram demonstrates extent of dilatation of aorta and innominate artery. (L.A.O. projection.)

Another possibility is that these aneurysms are an unusual expression of an inherited connective tissue disorder such as Marfan's syndrome. There was neither a history nor evidence of any similar condition in the siblings who were examined, but it must be stated that, owing to the polygamous character of our patients, such examinations were not comprehensive. None of the other stigmata of Marfan's syndrome were noted in any patient despite careful search, which on most occasions included a specialist ophthalmological opinion. We have not been able to find any record of anthropometric measurements on West African adult negroes, but measurements we made on several of these patients did not differ significantly from those obtained in a small series of healthy adult negroes. Finally there is no resemblance either histologically, macroscopically, or in behaviour, between the aneurysms which we describe here and the dissecting aneurysms of the aorta with rupture of that vessel which occur in Marfan's syndrome. For these reasons we believe that the two diseases are distinct.

In 1908 Takayashu described a condition in which the complete absence of arterial pulsation in the main arterial trunks arising from the aortic arch was accompanied by serious ocular complications. Since then numerous reports have appeared under the titles of Takayashu's syndrome, pulseless disease, aortic arch syndrome, and young female arteritis. The majority of these patients are women of Japanese extraction, but the disease seems to occur in most races and Ross and McKusick (1953) reviewed over a hundred reported cases. The pathological basis of this disease is an obliterating thromboarteritis of the main vessels which arise from the aortic arch, and it has been suggested that in some cases inflammation may play a part. Aneurysmal dilatation of these vessels is not usually a feature of the disease although Cosma et al. (1959) have reported a case from Japan in which this apparently did occur. It has already been stated that diminution or absence of the pulses in one or both upper limbs occurred in four of our patients, but these abnormalities are easily explained by the anatomical sites of the aneurysms. For this and other reasons given below we do not think these are cases of pulseless disease. McGuire et al. (1958) described 5 patients who had "chronic aortitis of undetermined cause with severe and fatal aortic insufficiency." They reported gross thickening of the aorta in these patients - in one instance the aortic wall was $0.9 \mathrm{~cm}$. thick at necropsy - and stated that the process never extended below the diaphragm nor spread to the major branches of the aorta. Thickening of the wall of the aorta was not a common feature in our cases, the abdominal aorta was frequently affected, and involvement of the main branches of the aortic arch was the rule. In the one necropsy there was no histological evidence of arteritis, and 


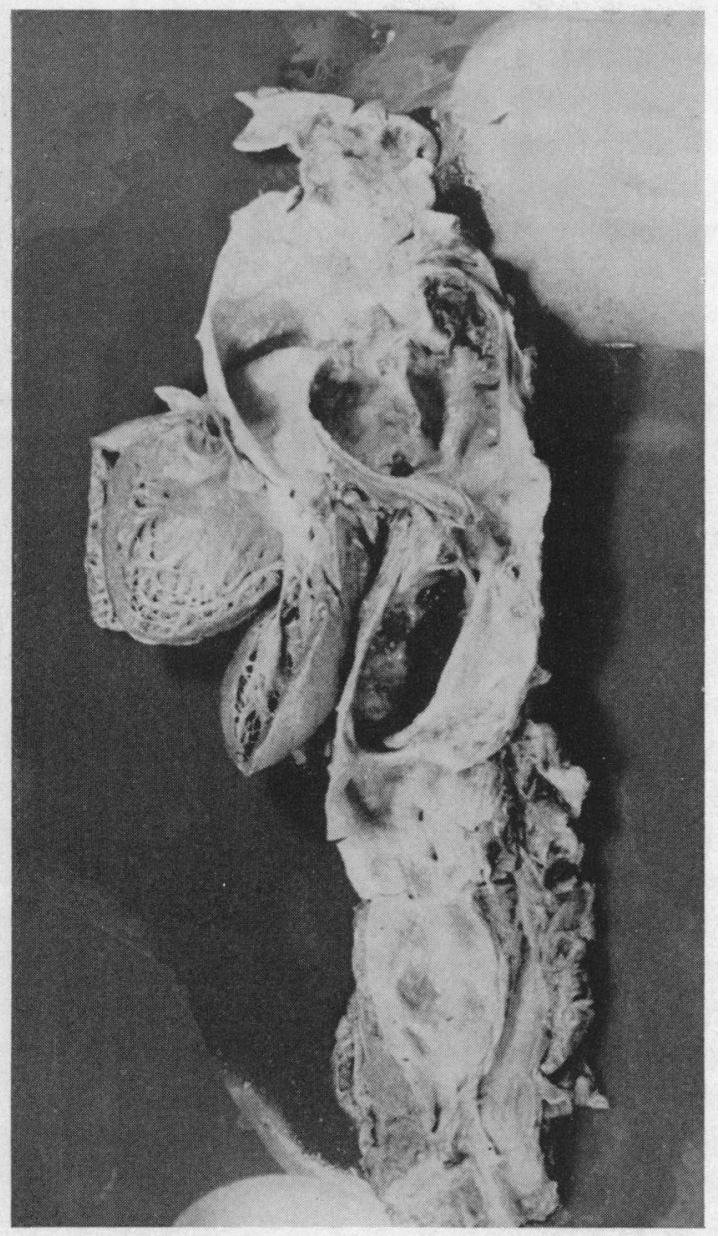

FIG. 7.-(Case 2). Specimen shows that the whole of the aorta is dilated. Several dilated pouches contain laminated thrombus. we think that all these features distinguish the present series from "pulseless disease" and from the condition described by McGuire et al. Similarly aortitis due to tuberculosis (Meehan et al., 1957) can be discounted in the rtiology.

Nevertheless it must be admitted that these aneurysms could be the end-result of an arteritis which has "burnt out" and caused localized dilatations of the affected vessels without histological evidence at this late stage of the original inflammation. Some support is lent to this view by recent case reports by Gelfand (1955), Isaacson et al. (1959) and by Jacobson (1960). Gelfand's patient was an African child, two years of age, with aneurysms in the thoracic and abdominal aortæ, and in the right subclavian artery. Histological examination showed that the media was the seat of an inflammatory process with giant cell formation, and Gelfand thought the condition was the giant-cell arteritis described by Gilmour (1941). Isaacson et al. (1959), writing from Johannesburg, described two African girls with aortitis and stated that they had seen two further children with the same condition. In one of these children the arch and the first part of the ascending aorta were dilated. Jacobson's patient, a child of 8 , was shown to have multiple saccular aneurysms of the thoracic aorta. The process did not extend below the diaphragm. It must therefore be accepted that aneurysm formation may accompany or follow arteritis. The youth of these patients, and the fact that they were all African, tempts one to suspect that they may be portraying the earlier stages of the same disease which we describe here.

Ponsetti and Baird (1952) first reported the experimental production of dissecting aneurysms of the aorta in very young rats fed a diet containing 50 per cent sweet-pea seeds (Lathyrus odoratus). The active principle responsible has been identified as $\beta$-aminopropionitrile (Schilling and Strong, 1954). So far as we are aware such lesions have not been reported in humans, and none of our subjects had any clinical evidence of lathyrism.

Theoretically it is possible that parasite infestations may be responsible. Williams (1887) seems to have been the first to show that the large blood vessels of the horse could be invaded by Strongylus Armatus. The worms burrow into the vessel wall and aneurysmal dilatation ensues. These helminths can be seen by the naked eye, and are obvious on histological section. Aneurysms due to strongyloides have not been reported in humans, and there is no reason to suppose that they had anything to do with the vascular lesions which we describe. Further, the normal eosinophil counts in four of our patients do not suggest any significant parasitic burden (Table II).

It is impossible to deny that a localized congenital weakness in the vessel wall may be responsible for these aneurysms. The youngest member of the series reported here was sixteen years old, but 


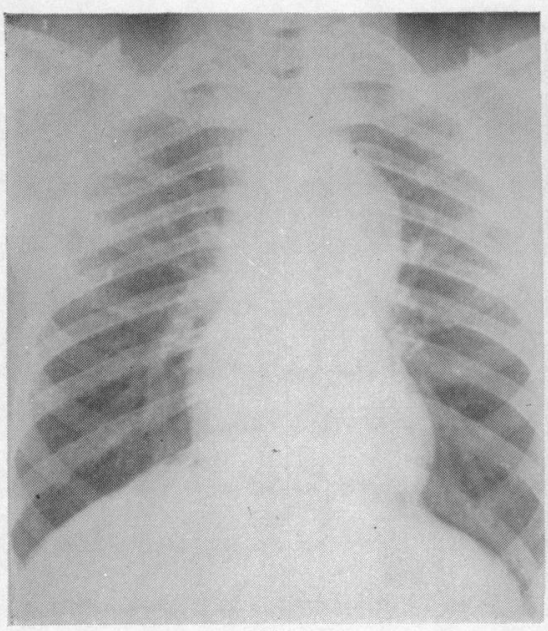

(A)

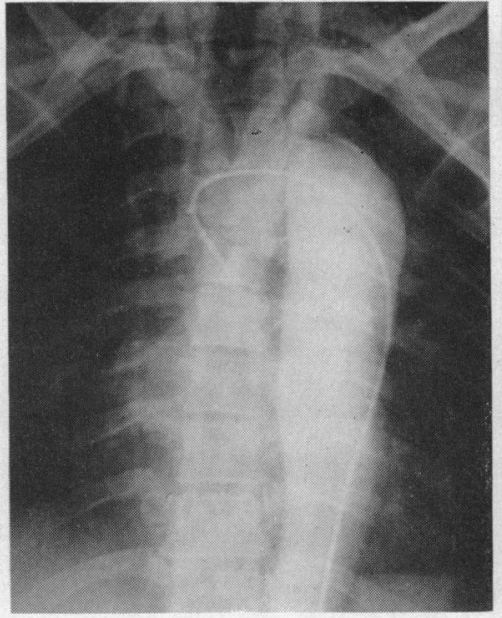

(B)

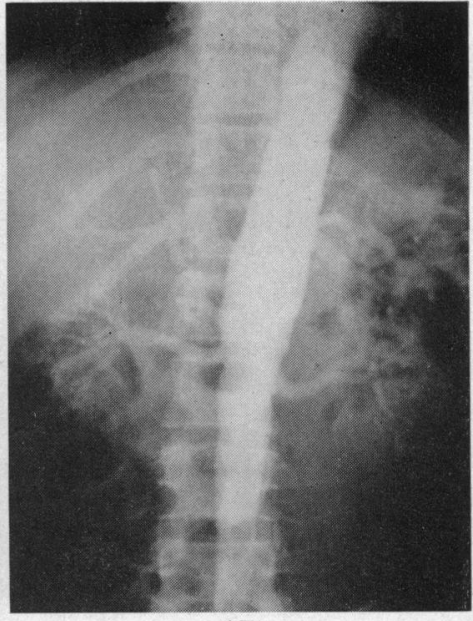

(C)

FIG. 8.-(Case 7). (A) Dilated arch and descending aortæ evident on plain chest film. (B) Retrograde aortogram confirms aortic dilatation. (C) Aortic dilatation extends to just beyond level of renal arteries. Renal vasculature normal.

it is reasonable to suppose that the full-blown lesion may take some time to develop, and this may explain why we have not encountered the syndrome in childhood or infancy.

\section{SUMMARY}

Seven young Nigerians are described in whom multiple aneurysms of the aorta and the main branches of the arch of the aorta occurred. These were defined by angiocardiography and the symptoms and physical signs are briefly described. The risk of secondary hypertension in those with abdominal aneurysms is emphasized. The possible rtiology is discussed and it is suggested that the aneurysms are caused either by localized congenital weaknesses in the walls of the vessels, or are the late sequelæ of an arteritis.

We are indebted to Dr. J. G. Jackson for the necropsy findings in Case 2. We wish to thank Mr. Frank Speed of the Department of Medical Illustration for the reproductions of radiographs.

\section{REFERENCES}

Abrahams, D. G., and Parry, E. H. O. (1961). Circulation, in the press.

Cosma, J., Maruyama, Y., Pettet, J. R., and Cutshall, V. (1959). Circulation, 20, 267.

Edozien, J. C. (1958). W. Afr. med. J., 7, 121.

Gelfand, M. (1955). Brit. Heart J., 17, 264.

Gilmour, J. R. (1941). J. Path. Bact., 53, 263.

Isaacson, C., Klachko, D. M., Wayburne, S., and Simpson, I. W. (1959). Lancet, $2,542$.

Jacobson, B. (1960). Brit. J. Radiol., 33, 523.

McGuire, J., Scott, R. C., and Gall, E. A. (1958). Amer. J. med. Sci., 235, 394.

Meehan, J. J., Pastor, B. M., and Torre, A. V. (1957). Circulation, 16, 615.

Ponsetti, I. V., and Baird, W. A. (1952). Amer. J. Pathol., 28, 1059.

Ross, R. S., and McKusick, V. A. (1953). Arch. intern. Med., 92, 701.

Scott, J. W., Maxwell, E. S., and Grimes, A. E. (1949). Amer. Heart J., 38, 34.

Schilling, E. D., and Strong, F. M. (1954). J. Amer. chem. Soc., 76, 2848.

Takayashu, M. (1908). Acta. Soc. ophthl. jap., 12, 554.

Williams, W. L. (1887). Vet. J., 25, 159. 